\title{
Safety and efficacy of different anticoagulation regimens after left atrial appendage occlusion
}

\author{
Wei Li ${ }^{1,2}$, Runfeng Gao ${ }^{1}$, Juan Zhao ${ }^{3}$, Yin Ren², Gecai Chen ${ }^{2}$, Junguo Zhu ${ }^{2}$, Kai Jin ${ }^{2}$, Li Zhu', \\ Zhongbao Ruan ${ }^{1,2}$ \\ ${ }^{1}$ Graduate School of Dalian Medical University, Dalian, China; ${ }^{2}$ Department of Cardiology, Taizhou People's Hospital, Taizhou, China; ${ }^{3}$ Medical \\ College of Nantong University, Nantong, China \\ Contributions: (I) Conception and design: W Li; (II) Administrative support: W Li; (III) Provision of study materials or patients: W Li, Z Ruan; (IV) \\ Collection and assembly of data: W Li, R Gao; (V) Data analysis and interpretation: W Li, R Gao; (VI) Manuscript writing: All authors; (VII) Final \\ approval of manuscript: All authors. \\ Correspondence to: Zhongbao Ruan. Graduate School of Dalian Medical University, Dalian 116000, China; Department of Cardiology, Taizhou \\ People’s Hospital, Taizhou 225300, China. Email: tzcardiac@163.com.
}

Background: This study examined the safety and efficacy of different anticoagulation regimens in patients with atrial fibrillation (AF) after left atrial appendage occlusion (LAAC) using the Watchman closure device.

Methods: AF patients who underwent LAAC using the Watchman closure device in the Department of Cardiology, Jiangsu Taizhou People's Hospital between March 2018 and November 2019 were retrospectively enrolled in this study. Patients were divided into two groups according to different postoperative anticoagulant regimens. One group was treated with anticoagulant therapy alone [oral anticoagulant (OAC)/new OAC (NOAC) group] and the other was given NOACs combined with single antiplatelet therapy (SPAT) (NOAC + SAPT group). The incidences of ischemic stroke/transient ischemic attack (TIA), major bleeding events, all-cause mortality, and device-related thrombosis (DRT) were recorded. Furthermore, multivariate regression was used to analyze the factors associated with the occurrence of early DRT.

Results: A total of 160 patients, including 42 (51\%) females, with a mean age of $69.13 \pm 6.14$ years were enrolled in this study. The mean $\mathrm{CHA}_{2} \mathrm{DS}_{2}$-VASc score was 3.66 \pm 1.11 and the mean HAS-BLED score was 4.16 \pm 0.82 . During the postoperative follow-up period, there were no significant differences in the incidence of ischemic stroke/TIA [hazard ratio $(\mathrm{HR})=0.616$; 95\% confidence interval (CI): 0.056 to 6.818 ; $\mathrm{P}=0.693$ ], major bleeding events $(\mathrm{HR}=0.520 ; 95 \% \mathrm{CI}: 0.047$ to $5.764 ; \mathrm{P}=0.594)$ nor all-cause mortality $(\mathrm{HR}=0.579$; 95\% CI: 0.052 to 6.394; $\mathrm{P}=0.656$ ) between the two groups. However, the incidence of early DRT was higher in the OAC/NOAC group compared to the NOAC + SAPT group [odds ratio (OR) =0.120; 95\% CI: 0.015 to $0.984 ; \mathrm{P}=0.048]$. Multivariate regression confirmed that atrial blood stasis $(\mathrm{OR}=11.367 ; 95 \% \mathrm{CI}: 1.394$ to $92.687 ; \mathrm{P}=0.023)$ and peri-device leak $(\mathrm{OR}=9.337 ; 95 \% \mathrm{CI}: 1.623$ to $53.727 ; \mathrm{P}=0.012)$ were independent predictors of early DRT.

Conclusions: Short-term NOAC + SAPT after LAAC did not significantly increase the incidence of major bleeding events, ischemic stroke/TIA, nor all-cause mortality compared to OAC/NOAC therapy. Not only was NOAC + SAPT therapy found to be safe and effective in short-term follow-up, but it also lowered the risk of early DRT.

Keywords: Atrial fibrillation (AF); left atrial appendage occlusion (LAAC); anticoagulation therapy; safety

Submitted Nov 18, 2021. Accepted for publication Jan 07, 2022.

doi: 10.21037/apm-21-3654

View this article at: https://dx.doi.org/10.21037/apm-21-3654 


\section{Introduction}

Atrial fibrillation (AF) is the most common arrhythmia, with more than 33 million patients affected worldwide (1). AF patients are at risk of thrombus and stroke, and the left atrial appendage (LAA) is the most common site of thrombosis. If untreated, $\mathrm{AF}$ patients have a 4-5 fold increased risk of ischemic stroke in all age groups. Transesophageal echocardiography (TEE) shows that atrial thrombus is present in about $5-15 \%$ of $\mathrm{AF}$ patients, and $91 \%$ of these thrombi are located in the LAA of patients with nonrheumatic AF (2). As the population ages, the incidence of AF continues to rise, accompanied by an increase in stroke and thromboembolic events. The $\mathrm{CHA}_{2} \mathrm{DS}_{2}$-VASc score is commonly used to assess the risk of a thrombotic event in patients with AF. Although oral anticoagulants (OACs) can be used for preventing stroke in patients with a high $\mathrm{CHA}_{2} \mathrm{DS}_{2}$-VASc score, the long-term use of OAC has the disadvantages of high bleeding risk, poor patient compliance, and heavy economic burden. A large proportion of patients are unable to adhere to anticoagulant therapy for a long time, and some patients with highrisk of bleeding are considered unsuitable for this therapy. Recently, the novel LAA closure device was introduced to prevent thromboembolisms in patients who are not suitable for OAC therapy. The PREVAIL and PROTECT-AF trials demonstrated that in patients with non-valvular AF (NVAF), LAA occlusion (LAAC) was comparable to OAC for stroke prevention. It was shown to be safe and effective and is now an alternative for preventing stroke in such patients (3-5). The 2016 European Society of Cardiology (ESC) guidelines for the management of AF (6) and the 2019 American Heart Association (AHA)/American College of Cardiology (ACC)/American Heart Rhythm Society (HRS) guidelines for the management of $\mathrm{AF}$ (7) have now included LAAC in the Class IIb recommendation for preventing stroke in patients with NVAF who have contraindications to long-term anticoagulation. Clinically, the Watchman closure device (Boston, USA) is currently used to occlude the LAA, and its efficacy has been verified (8). After LAAC, anticoagulant drugs are still required for device-related thrombosis (DRT) and potential stroke events. However, it remains inconclusive as to which anticoagulation regimen can minimize the incidence of DRT and stroke, while also minimizing bleeding events.

The recommended anticoagulation regimen in the PROTECT-AF (9) trial is warfarin and aspirin for 45 days, followed by aspirin and clopidogrel up to 6 months, and finally, lifelong use of aspirin. However, the anticoagulant effect of warfarin is vulnerable to drugs and food, and patients treated with warfarin need to be frequently monitored for their international normalized ratio (INR) due to the high risk of bleeding and low compliance in such patients. At present, non-vitamin $\mathrm{K}$ antagonist (nonVKA) OACs [also known as new OACs (NOACs)] are an alternative to VKAs in the prevention of stroke in AF patients. Indeed, NOACs have gradually become the firstchoice treatment, especially for patients just beginning anticoagulant therapy (10). Recently, NOACs combined with single antiplatelet therapy (SAPT) was found to be safe and effective for the treatment of thrombotic events (11) and is used for the secondary prevention of cardiovascular disease. A meta-analysis including 36 study groups and 4,474 patients after LAAC shows that for patients with nonabsolute anticoagulant contraindications, anticoagulant therapy rather than dual antiplatelet therapy (DAPT) should be actively selected. NOACs displayed potential for further development (12). However, there are few studies on which anticoagulant drug is the optimal choice after LAAC. Therefore, this current study evaluated the safety and efficacy of different anticoagulants used after LAAC by comparing two regimens, namely, anticoagulant therapy alone (OAC/NOAC) and NOAC combined with SPAT (NOAC + SAPT). This study aimed to provide a safe and effective rehabilitation program for AF patients after LAAC and to improve patient outcomes. We present the following article in accordance with the STROBE reporting checklist (available at https://apm.amegroups.com/article/ view/10.21037/apm-21-3654/rc).

\section{Methods}

\section{Study subjects}

AF patients who underwent LAAC in the Department of Cardiology, Jiangsu Taizhou People's Hospital between March 2018 and November 2019 were retrospectively enrolled. All procedures performed in this study involving human participants were in accordance with the Declaration of Helsinki (as revised in 2013). The study was approved by ethics board of Taizhou People's Hospital (No. KY 202008001) and informed consent was taken from all the patients.

Patients were included if they satisfied the following: (I) aged 18 years and older with NVAF; (II) had $\mathrm{CHA}_{2} \mathrm{DS}_{2}-$ VASc score $\geq 2$; (III) could not tolerate anticoagulation for a long period or had contraindications to anticoagulation; and (IV) had indications for LAAC which was successfully 
performed using a Watchman closure device. The device must be stable, as confirmed by a tug test, and be successfully released, with a peri-device leak $<5 \mathrm{~mm}$ after release, and a compression ratio of $8-30 \%$. The device is positioned slightly distal to or just at the LAA ostium.

Patients were excluded if they presented with the following: (I) valvular AF; (II) left atrial diameter $>65 \mathrm{~mm}$; (III) atrial thrombus detected by preoperative TEE or cardiac computed tomography angiography (CCTA); (IV) a history of stroke within 1 month; (V) pericardial effusion or massive hemorrhage during surgery; or (VI) LAAC was performed with a closure device other than the Watchman closure device.

\section{Postoperative treatment regimens}

Postoperatively, patients were treated with anticoagulants for 3 months, which included anticoagulant therapy alone (OAC/NOAC) or NOAC combined with antiplatelet medications (NOAC + SAPT). Specifically, the OAC/ NOAC therapy referred to warfarin (INR maintained at 2-3), rivaroxaban (15 $\mathrm{mg}$ once a day), and dabigatran (110 mg twice a day). The NOAC+SAPT therapy referred to rivaroxaban $(15 \mathrm{mg}$ once a day) + aspirin $(0.1 \mathrm{~g}$ once a day)/clopidogrel (75 mg once a day), and dabigatran (110 mg twice a day $)+\operatorname{aspirin}(0.1 \mathrm{~g}$ once a day $) /$ clopidogrel (75 mg once a day). TEE or CCTA was repeated 3 months later. If there was no DRT and the peri-device leak was $<5 \mathrm{~mm}$, these 2 regimens were changed to aspirin $(0.1 \mathrm{~g}$, once a day) + clopidogrel ( $75 \mathrm{mg}$, once a day) for 3 months, followed by aspirin $(0.1 \mathrm{~g}$, once a day) or clopidogrel (75 mg, once a day) for life-long treatment.

The patients were divided into the OAC/NOAC and NOAC + SAPT groups according to different anticoagulation regimens in the first 3 months after surgery. Their baseline data were recorded, including gender, age, smoking history, type of AF, glomerular filtration rate (GFR), hypertension, diabetes, history of previous stroke/ transient ischemic attack (TIA), coronary heart disease, left ventricular ejection fraction (LVEF), AF stroke risk (assessed using the $\mathrm{CHA}_{2} \mathrm{DS}_{2}$-VASc score) and bleeding risk (assessed using the HAS-BLED score).

\section{Postoperative follow-up}

The median follow-up period was 14.5 months (interquartile range, 9-21 months). During follow-up, the following information of the study subjects was recorded: incidence of ischemic stroke/TIA, major bleeding events (13), all-cause mortality, and early DRT (defined as blood clots attached to the closure device on the left atrial side detected by TEE or CCTA 3 months after LAAC).

\section{Statistical analysis}

All data were statistically analyzed using SPSS 24.0 software. The measurement data conforming to normal distribution was expressed as mean \pm standard deviation $(\mathrm{SD})$, and the comparison between the two groups was analyzed by $t$-test. Enumeration data were expressed as n (\%), and the chisquare test was used for comparison between two groups. A univariate Cox regression model was used for analyzing the prognosis of different anticoagulant regimens, and multivariate logistics regression was performed to determine the factors influencing early DRT. A P value $<0.05$ was considered statistically significant.

\section{Results}

\section{Baseline data of patients}

A total of 160 patients, including 42 (51\%) females, with a mean age of $69.13 \pm 6.14$ years were enrolled in this study. The mean $\mathrm{CHA}_{2} \mathrm{DS}_{2}-\mathrm{VASc}$ score was $3.66 \pm 1.11$ and the mean HAS-BLED score was $4.16 \pm 0.82$. Patients received either OAC/NOAC regimen $(\mathrm{n}=82)$ or NOAC + SAPT regimen $(n=78)$ in the first 3 months after LAAC. Specifically, warfarin was administrated in 27 cases $(17 \%)$, dabigatran in 28 cases (18\%), rivaroxaban in 27 cases (17\%), and dabigatran + SAPT in 39 cases (24\%). As shown in Table 1, there were no significant differences between the two groups in terms of gender, age, smoking history, type of AF, GFR, hypertension, diabetes, previous history of stroke/ TIA, coronary heart disease, LVEF, $\mathrm{CHA}_{2} \mathrm{DS}_{2}-\mathrm{VASc}$, nor HAS-BLED scores, indicating that the two groups were comparable.

\section{Effects of different anticoagulation regimens on the incidence of postoperative adverse reactions}

After 14.5 months of follow-up, the incidence of ischemic stroke/TIA, major bleeding events, all-cause mortality, and DRT was recorded. The annual incidence of ischemic stroke/TIA, major bleeding, and all-cause mortality in the OAC/NOAC group was $1.8 \%, 2.1 \%$, and $1.9 \%$, respectively, while in the NOAC + SAPT group, it was 
Table 1 Baseline characteristic of the patients

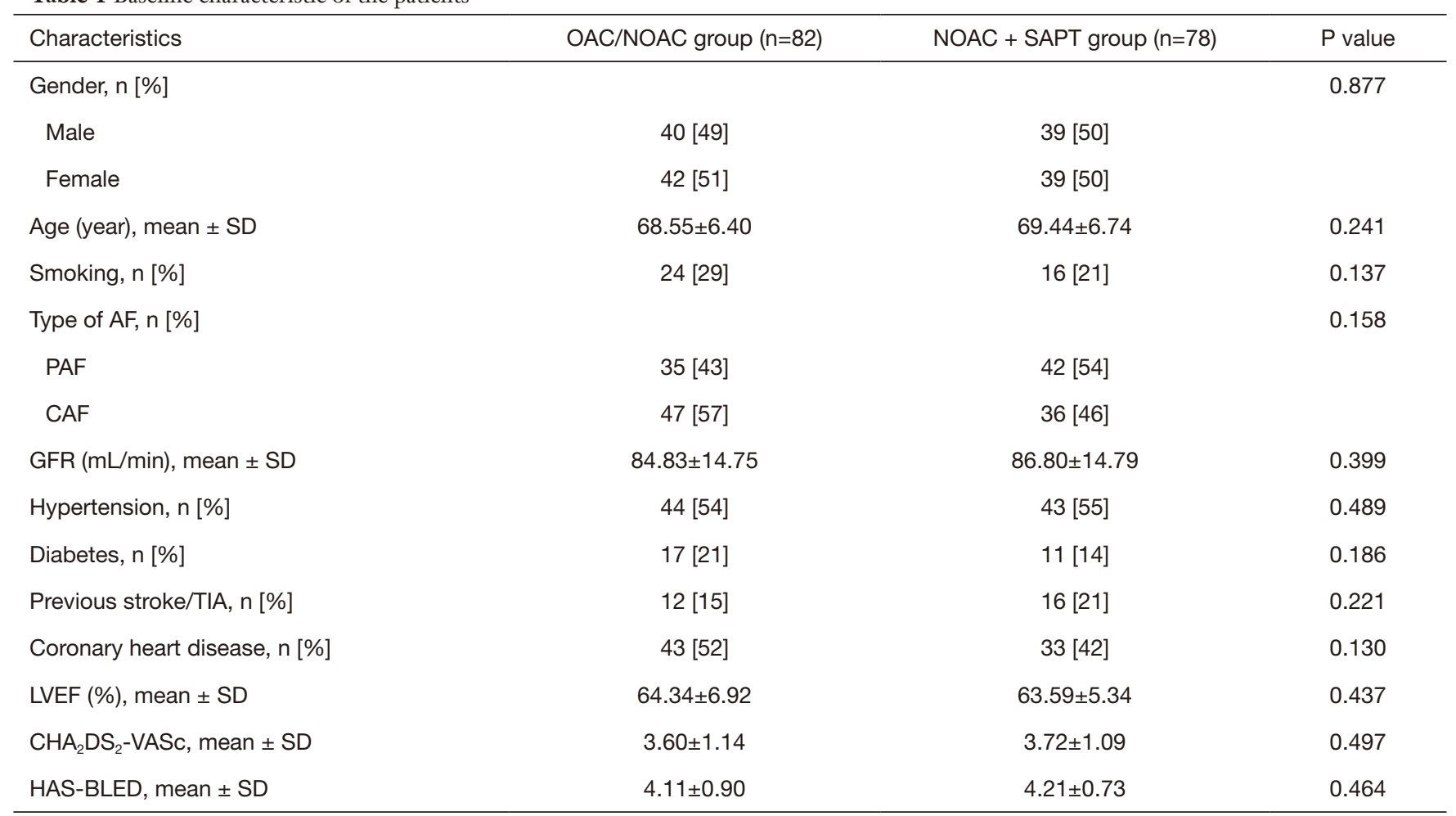

OAC, oral anticoagulant; NOAC, new OAC; SAPT, single antiplatelet therapy; SD, standard deviation; AF, atrial fibrillation; PAF, paroxysmal atrial fibrillation; CAF, chronic atrial fibrillation; GFR, glomerular filtration rate; TIA, transient ischemic attack; LVEF, left ventricular ejection fraction.

$1.1 \%, 1.1 \%$, and $1.1 \%$, respectively (Table 2 ). There were no significant differences in the incidence of stroke/TIA [hazard ratio $(\mathrm{HR})=0.616 ; 95 \%$ confidence interval $(\mathrm{CI})$ : 0.056 to $6.818 ; \mathrm{P}=0.693$ ], major bleeding $(\mathrm{HR}=0.520 ; 95 \%$ CI: 0.047 to $5.764 ; \mathrm{P}=0.594$ ), nor all-cause mortality (HR $=0.579 ; 95 \%$ CI: 0.052 to $6.394 ; \mathrm{P}=0.656$ ) between the two groups.

All patients underwent at least one TEE or CCTA examination during the follow-up period (Figure $1 A-1 \mathrm{~F}$ ). During the first follow-up at 3 months after LAAC, a total of 8 patients (5\%) experienced DRT, and 2 of 8 patients had early DRT with stroke. One patient with DRT was found at the 12-month of follow-up. The incidence of early DRT was $9.8 \%$ in the OAC/NOAC group, including 3 cases of warfarin, 3 cases of dabigatran, and 2 cases of rivaroxaban. The incidence of early DRT was $1.3 \%$ in the NOAC + SAPT group, including 1 case of dabigatran + SAPT and 0 case of rivaroxaban + SAPT. There was a significant difference in the incidence of DRT between the two treatment groups (HR $=0.120$; 95\% CI: 0.012 to 0.984; $\mathrm{P}=0.048$; Table 2), suggesting that different anticoagulation regimens could affect the incidence of postoperative DRT.

\section{Multivariate logistic regression analysis of factors influencing early DRT}

A multivariate logistics regression model was used to further analyze the risk factors affecting the occurrence of early DRT. The results revealed no significant correlation between the occurrence of early DRT and age, gender, smoking history, hypertension, diabetes, coronary heart disease, history of previous stroke/TIA, types of AF, nor LVEF. However, left atrial blood stasis [odds ratio (OR) $=11.367 ; 95 \%$ CI: 1.394 to $92.687 ; \mathrm{P}=0.023]$ and peri-device leak $(\mathrm{OR}=9.337 ; 95 \% \mathrm{CI}: 1.623$ to $53.727 ; \mathrm{P}=0.012)$ were significantly associated with the occurrence of early DRT and may be independent predictors of early DRT (Table 3).

\section{Discussion}

AF occurs most frequently among sustained arrhythmias, affecting more than 33 million patients worldwide (1). 
Table 2 Univariate regression analysis of the relationship between postoperative clinical adverse events and anticoagulation regimens

\begin{tabular}{|c|c|c|c|c|c|c|}
\hline Endpoint events & Total $(n=160)$ & $\begin{array}{l}\text { OAC/NOAC group } \\
(n=82)\end{array}$ & $\begin{array}{c}\text { NOAC + SAPT group } \\
\qquad(n=78)\end{array}$ & HR & $95 \% \mathrm{Cl}$ & $P$ value \\
\hline \multicolumn{7}{|l|}{ Ischemic stroke/TIA } \\
\hline Number of events (patient-year) & 3 & 2 & 1 & & & \\
\hline Total patient-years & 196 & 101 & 95 & & & \\
\hline Number of events (patient-year) & 3 & 2 & 1 & & & \\
\hline Incidence of events (\%) & 1.5 & 2.0 & 1.1 & 0.520 & $0.047-5.764$ & 0.594 \\
\hline \multicolumn{7}{|l|}{ All-cause mortality } \\
\hline Incidence of events (patient-year) & 1.5 & 1.9 & 1.1 & 0.579 & $0.052-6.394$ & 0.656 \\
\hline DRT & 9 & 8 & 1 & 0.120 & $0.015-0.984$ & $0.048^{*}$ \\
\hline
\end{tabular}

*, P<0.05. OAC, oral anticoagulant; NOAC, new OAC; SAPT, single antiplatelet therapy; HR, hazard ratio; Cl, confidence interval; TIA, transient ischemic attack; DRT, device-related thrombosis.

Thromboembolic events are well-known complications of AF, especially in ischemic stroke. The risk of ischemic stroke is 4-5 times higher in AF patients compared to patients with sinus arrhythmias, but OACs can significantly reduce the risk (14). Indeed, OAC therapy is recommended for the prevention of thromboembolic events in NVAF patients (15).

AF patients with contraindications to anticoagulants have increased likelihood of bleeding. Conversely, it is not recommended that patients at high risk of stroke stop their anticoagulation therapy. LAAC is a device-based alternative to OACs for preventing stroke in patients who are not candidates for long-term OAC therapy. After LAAC, the risk of thrombosis on the surface of the implanted device is high, and thus, anticoagulant or antiplatelet therapy is required until the epithelialization is finally achieved. Such postoperative therapy can decrease the incidence of adverse events in patients (16). However, the optimal type of treatment and the optimal duration of therapy remains unclear. Propensity-matched comparison in 2,812 NVAF patients by Søndergaard et al. found that after LAAC using the Watchman closure device, $92 \%$ of patients who were treated with 45-day anticoagulant therapy (including warfarin and NOAC + SAPT) had lower incidence of DRT compared to patients treated with SAPT therapy.
However, the incidence of bleeding events was similar between the two groups (17). The Pioneer-AF PCI (18) and AUGUSTUS (19) trials confirmed that patients with $\mathrm{AF}$ and coronary heart disease who undergo percutaneous coronary intervention have fewer adverse reactions after 6-12 months of NOAC + SAPT therapy. In addition, another AUGUSTUS trial (19) showed that the risk of bleeding in patients receiving apixaban + clopidogrel was significantly lower than that patients who were administered warfarin + aspirin. This suggested that the combination regimen of "NOAC + SAPT" for anticoagulation management after LAAC may be an effective alternative to "warfarin + SAPT". This current study compared OAC/ NOAC therapy with NOAC + SAPT regimen. There was no significant difference between the two treatments in the annual incidence rate of ischemic stroke/TIA, major bleeding events, nor all-cause mortality after LAAC. However, the incidence of early DRT was significantly lower in the NOAC + SAPT group compared to the OAC/ NOAC group. Contrary to the AUGUTUS trial (19), we found that NOAC + SAPT therapy achieved a lower incidence of major bleeding events, and this may be related to the shorter duration of combined anticoagulation in our study. Collectively, LAAC followed by a 3 -month NOAC + SAPT regimen was safe and effective in patients without 

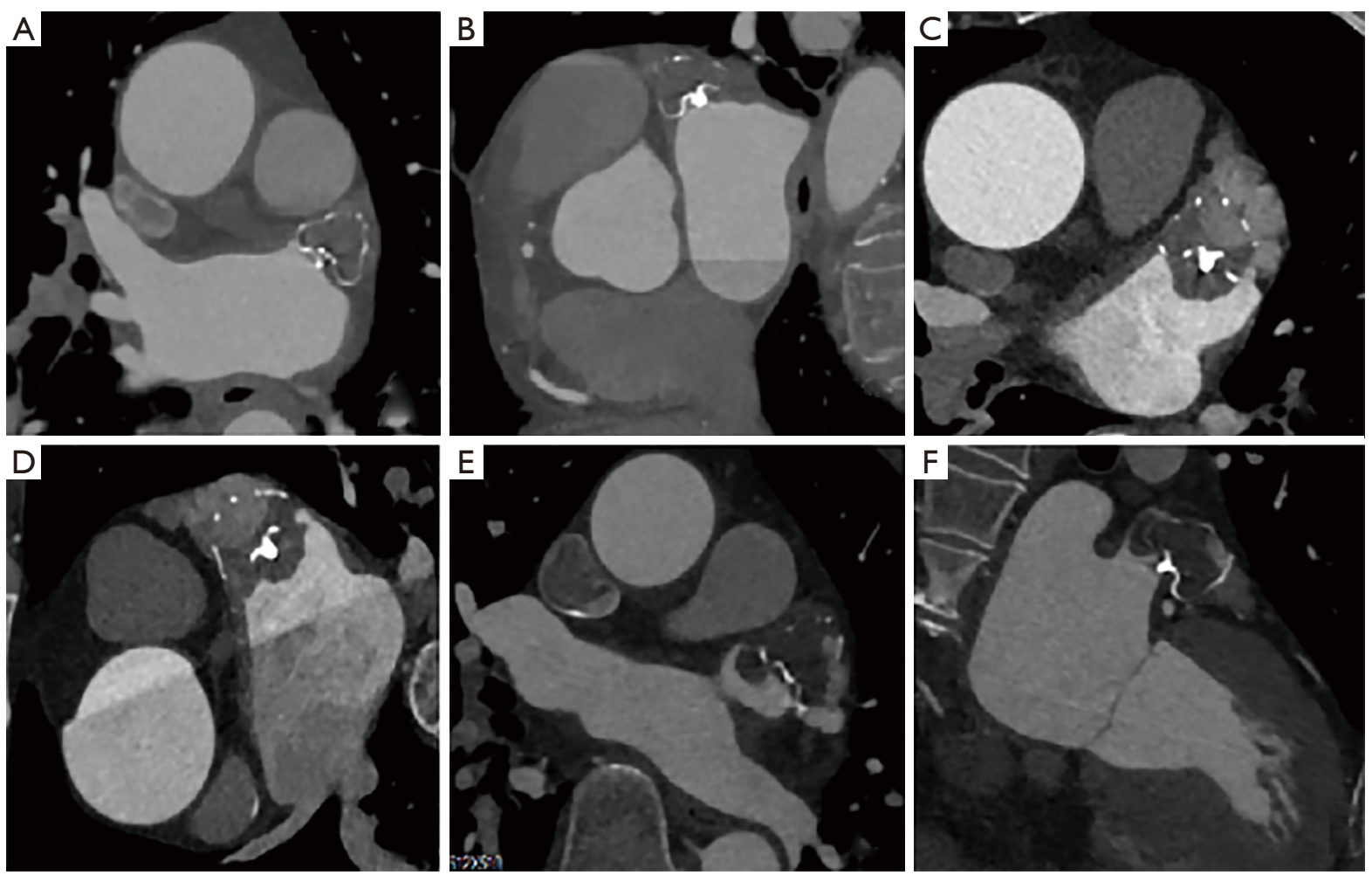

Figure 1 CCTA images of patients with DRT. (A,B) Patients with complete endothelialization of the LAA closure device. (C,D) Patients with thrombus attached to the closure device on the left atrial side, accompanied by with incomplete endothelialization of the device (leakage of contrast agent across the fabric on the device surface). (E,F) Patients with thrombus attached to the closure device on the left atrial side, accompanied by peri-device leak. CCTA, cardiac computed tomography angiography; DRT, device-related thrombosis; LAA, left atrial appendage.

Table 3 Multivariate logistic regression analysis of factors influencing early DRT

\begin{tabular}{llll}
\hline Variables & OR & 95\% Cl & P value \\
\hline Age & 0.968 & $0.851-1.099$ & 0.612 \\
Gender & 1.539 & $0.270-8.781$ & 0.627 \\
Smoking history & 0.338 & $0.034-3.343$ & 0.354 \\
Hypertension & 1.359 & $0.260-7.090$ & 0.716 \\
Diabetes & 1.044 & $0.131-8.308$ & 0.968 \\
Coronary heart disease & 4.793 & $0.686-33.480$ & 0.114 \\
Left atrial blood stasis & 11.367 & $1.394-92.687$ & $0.023^{*}$ \\
Previous stroke/TIA & 0.778 & $0.119-5.072$ & 0.793 \\
CAF & 0.524 & $0.098-2.809$ & 0.451 \\
LVEF (\%) & 0.935 & $0.820-1.066$ & 0.317 \\
Peri-device leak & 9.337 & $1.623-53.727$ & $0.012^{*}$ \\
\hline
\end{tabular}

*, $\mathrm{P}<0.05$. DRT, device-related thrombosis; OR, odds ratio; Cl confidence interval; TIA, transient ischemic attack; CAF, chronic atrial fibrillation; LVEF, left ventricular ejection fraction. 
contraindications to NOACs. However, future studies with larger sample size and longer follow-up periods are still warranted to confirm the clinical advantage of NOAC + SAPT regimen compared to OAC alone.

Several meta-analyses have shown that the overall incidence of DRT after LAAC with different closure devices varies significantly, ranging from $1.7 \%$ to $7.2 \%$ (20-23). In this study, the overall incidence of DRT was $5.6 \%$, with a total of 9 cases. Eight of 9 cases were found at the first follow-up at 3 months after LAAC. After the occurrence of DRT, the time of anticoagulation therapy was prolonged and 8 of the 10 DRT cases resolved by 3-6 months, and the other 2 patients remained on continuous anticoagulation. Among the patients with early DRT, 2 experienced stroke events.

There are many risk factors leading to DRT, including smoking, advanced age, permanent AF, history of stroke or TIA, vascular disease, platelet count, LVEF $<40 \%$, LAA enlargement, history of LAA thrombus, and left atrial spontaneous echo contrast $(21,24-26)$. In this study, multivariate logistic regression analysis confirmed that left atrial blood stasis and peri-device leak were independent predictors of early DRT. Left atrial blood stasis, also known as left atrial spontaneous echo contrast, is characterized by dynamic smoke-like echoes in the left atrium on TEE. By contrast, left atrial blood stasis is characterized by uneven filling of left atrial memory in the arterial phase on CCTA, and homogeneous diffusion of contrast agent after delayed scanning. Left atrial blood stasis is considered to be a manifestation of prothrombosis and may lead to DRT. Additionally, in patients with peri-device leak, the blood will enter the LAA through the leak, resulting in disordered blood flow within the LAA, delayed endothelialization, and increased risk of DRT (27). For the above-mentioned population with peri-device leak, intensive anticoagulation and close follow-up are particularly important during early endothelialization of the device. Whether DRT is associated with an increased risk of stroke or systemic embolism remains controversial. Dukkipati et al. demonstrated that DRT, if present, was associated with the incidence of stroke and systemic embolism after LAA occlusion using the Watchman device (20). However, in the EWOLUTION trial, the increased incidence of DRT did not increase the incidence of ischemic stroke events (28). The current study showed that the annual stroke rate of DRT patients (9.8\%) was significantly higher than that of non-DRT patients (1.0\%). However, the two groups could not be statistically compared as the sample size was too small, and there was a difference in the baseline data between the two groups.

\section{Conclusions}

After LAAC, 3-month NOAC + SAPT therapy did not increase the incidence of major bleeding events nor the incidence of ischemic stroke/TIA and all-cause mortality compared to 3-month OAC/NOAC therapy. Interestingly, not only was NOAC + SAPT therapy safe and effective in short-term follow-up, but it was also associated with a lower risk of early DRT. This study is a single-center retrospective study with a relatively small sample size and short follow-up time, which is likely to cause some deviations in the results. Therefore, longer-term follow-up studies with larger patient cohorts and multi-center clinical trials are warranted to further verify these conclusions.

\section{Acknowledgments}

Funding: None.

\section{Footnote}

Reporting Checklist: The authors have completed the STROBE reporting checklist. Available at https://apm. amegroups.com/article/view/10.21037/apm-21-3654/rc

Data Sharing Statement: Available at https://apm.amegroups. com/article/view/10.21037/apm-21-3654/dss

Conflicts of Interest: All authors have completed the ICMJE uniform disclosure form (available at https://apm. amegroups.com/article/view/10.21037/apm-21-3654/coif). The authors have no conflicts of interest to declare.

Ethical Statement: The authors are accountable for all aspects of the work in ensuring that questions related to the accuracy or integrity of any part of the work are appropriately investigated and resolved. All procedures performed in this study involving human participants were in accordance with the Declaration of Helsinki (as revised in 2013). The study was approved by ethics board of Taizhou People's Hospital (No. KY 202008001) and informed consent was taken from all the patients.

Open Access Statement: This is an Open Access article distributed in accordance with the Creative Commons Attribution-NonCommercial-NoDerivs 4.0 International 
License (CC BY-NC-ND 4.0), which permits the noncommercial replication and distribution of the article with the strict proviso that no changes or edits are made and the original work is properly cited (including links to both the formal publication through the relevant DOI and the license). See: https://creativecommons.org/licenses/by-nc-nd/4.0/.

\section{References}

1. Chugh SS, Havmoeller R, Narayanan K, et al. Worldwide epidemiology of atrial fibrillation: a Global Burden of Disease 2010 Study. Circulation 2014;129:837-47.

2. Moussa Pacha H, Al-Khadra Y, Soud M, et al. Percutaneous devices for left atrial appendage occlusion: A contemporary review. World J Cardiol 2019;11:57-70.

3. Holmes DR Jr, Kar S, Price MJ, et al. Prospective randomized evaluation of the Watchman Left Atrial Appendage Closure device in patients with atrial fibrillation versus long-term warfarin therapy: the PREVAIL trial. J Am Coll Cardiol 2014;64:1-12. Erratum in: J Am Coll Cardiol 2014;64:1186.

4. Reddy VY, Sievert H, Halperin J, et al. Percutaneous left atrial appendage closure vs warfarin for atrial fibrillation: a randomized clinical trial. JAMA 2014;312:1988-98. Erratum in: JAMA 2015;313:1061.

5. Reddy VY, Doshi SK, Kar S, et al. 5-Year Outcomes After Left Atrial Appendage Closure: From the PREVAIL and PROTECT AF Trials. J Am Coll Cardiol 2017;70:2964-75.

6. Kirchhof P, Benussi S, Kotecha D, et al. 2016 ESC Guidelines for the management of atrial fibrillation developed in collaboration with EACTS. Eur Heart J 2016;37:2893-962.

7. January CT, Wann LS, Calkins H, et al. 2019 AHA/ ACC/HRS Focused Update of the 2014 AHA/ACC/ HRS Guideline for the Management of Patients With Atrial Fibrillation: A Report of the American College of Cardiology/American Heart Association Task Force on Clinical Practice Guidelines and the Heart Rhythm Society in Collaboration With the Society of Thoracic Surgeons. Circulation 2019;140:e125-51.

8. Hou DM, Akinapelli A, Alex P, et al. Left atrial appendage closure-the Watchman device. Chinese Journal of Practical Internal Medicine 2015;35:991-7.

9. Holmes DR, Reddy VY, Turi ZG, et al. Percutaneous closure of the left atrial appendage versus warfarin therapy for prevention of stroke in patients with atrial fibrillation: a randomised non-inferiority trial. Lancet 2009;374:534-
42. Erratum in: Lancet 2009;374:1596.

10. Steffel J, Verhamme P, Potpara TS, et al. The 2018 European Heart Rhythm Association Practical Guide on the use of non-vitamin $\mathrm{K}$ antagonist oral anticoagulants in patients with atrial fibrillation. Eur Heart J 2018;39:1330-93.

11. Zhao LD, Liu S, Yin QY, et al. Study on the safety and clinical efficacy of new oral anticoagulants combined with antiplatelets in the treatment of restenosis after stenting of lower extremity arteries. Clinical Research 2021;29:65-6.

12. Li SY, Wang J, Hui X, et al. Meta-analysis of postoperative antithrombotic therapy after left atrial appendage occlusion. J Int Med Res 2020;48:300060520966478.

13. Mehran R, Rao SV, Bhatt DL, et al. Standardized bleeding definitions for cardiovascular clinical trials: a consensus report from the Bleeding Academic Research Consortium. Circulation 2011;123:2736-47.

14. Benjamin EJ, Blaha MJ, Chiuve SE, et al. Heart Disease and Stroke Statistics-2017 Update: A Report From the American Heart Association. Circulation 2017;135:e146603. Erratum in: Circulation 2017;135:e646. Erratum in: Circulation 2017;136:e196.

15. Raparelli V, Proietti M, Cangemi R, et al. Adherence to oral anticoagulant therapy in patients with atrial fibrillation. Focus on non-vitamin K antagonist oral anticoagulants. Thromb Haemost 2017;117:209-18.

16. Gorczyca-Michta I, Wożakowska-Kapłon B. Percutaneous left atrial appendage occlusion: New perspectives for the method. Cardiol J 2017;24:554-62.

17. Søndergaard L, Wong YH, Reddy VY, et al. PropensityMatched Comparison of Oral Anticoagulation Versus Antiplatelet Therapy After Left Atrial Appendage Closure With WATCHMAN. JACC Cardiovasc Interv 2019;12:1055-63.

18. Gibson CM, Mehran R, Bode C, et al. Prevention of Bleeding in Patients with Atrial Fibrillation Undergoing PCI. N Engl J Med 2016;375:2423-34.

19. Lopes RD, Heizer G, Aronson R, et al. Antithrombotic Therapy after Acute Coronary Syndrome or PCI in Atrial Fibrillation. N Engl J Med 2019;380:1509-24.

20. Dukkipati SR, Kar S, Holmes DR, et al. Device-Related Thrombus After Left Atrial Appendage Closure: Incidence, Predictors, and Outcomes. Circulation 2018;138:874-85.

21. Aminian A, Schmidt B, Mazzone P, et al. Incidence, Characterization, and Clinical Impact of DeviceRelated Thrombus Following Left Atrial Appendage Occlusion in the Prospective Global AMPLATZER Amulet Observational Study. JACC Cardiovasc Interv 2019;12:1003-14. 
22. Lempereur M, Aminian A, Freixa X, et al. Deviceassociated thrombus formation after left atrial appendage occlusion: A systematic review of events reported with the Watchman, the Amplatzer Cardiac Plug and the Amulet. Catheter Cardiovasc Interv 2017;90:E111-21.

23. Fauchier L, Cinaud A, Brigadeau F, et al. Device-Related Thrombosis After Percutaneous Left Atrial Appendage Occlusion for Atrial Fibrillation. J Am Coll Cardiol 2018;71:1528-36.

24. Sedaghat A, Schrickel JW, Andrié R, et al. Thrombus Formation After Left Atrial Appendage Occlusion With the Amplatzer Amulet Device. JACC Clin Electrophysiol 2017;3:71-5.

25. Saw J, Tzikas A, Shakir S, et al. Incidence and Clinical Impact of Device-Associated Thrombus and Peri-Device Leak Following Left Atrial Appendage Closure With the Amplatzer Cardiac Plug. JACC Cardiovasc Interv 2017;10:391-9.

26. Plicht B, Konorza TF, Kahlert P, et al. Risk factors for

Cite this article as: Li W, Gao R, Zhao J, Ren Y, Chen G, Zhu J, Jin K, Zhu L, Ruan Z. Safety and efficacy of different anticoagulation regimens after left atrial appendage occlusion. Ann Palliat Med 2022;11(1):201-209. doi: 10.21037/apm-21-3654 thrombus formation on the Amplatzer Cardiac Plug after left atrial appendage occlusion. JACC Cardiovasc Interv 2013;6:606-13.

27. Reddy VY, Doshi SK, Sievert H, et al. Percutaneous left atrial appendage closure for stroke prophylaxis in patients with atrial fibrillation: 2.3-Year Follow-up of the PROTECT AF (Watchman Left Atrial Appendage System for Embolic Protection in Patients with Atrial Fibrillation) Trial. Circulation 2013;127:720-9.

28. Boersma LV, Ince H, Kische S, et al. Evaluating RealWorld Clinical Outcomes in Atrial Fibrillation Patients Receiving the WATCHMAN Left Atrial Appendage Closure Technology: Final 2-Year Outcome Data of the EWOLUTION Trial Focusing on History of Stroke and Hemorrhage. Circ Arrhythm Electrophysiol 2019;12:e06841.

(English Language Editor: J. Teoh) 